www.jmscr.igmpublication.org Impact Factor 5.244

Index Copernicus Value: 83.27 ISSN (e)-2347-176x ISSN (p) 2455-0450 crossref DOI: https://dx.doi.org/10.18535/jmscr/v4i12.123

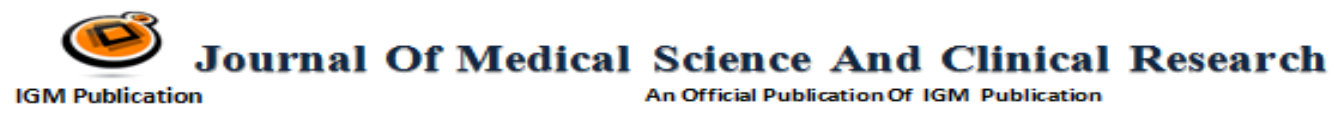

\title{
A Comparative Study of Maternal and Foetal Outcomes in Patients Undergoing Elective or Emergency Caesarean Section
}

\author{
Authors \\ P.Renuka ${ }^{1}$, V.Suguna ${ }^{2}$ \\ ${ }^{1}$ Junior resident, Obstetrics and Gynaecology, Mamata Medical College \& Hospital, Khammam \\ Email: renukammc@gmail.com \\ ${ }^{2}$ Associate professor, Obstetrics and Gynaecology, Mamata Medical College \& Hospital \\ Corresponding Author \\ V.Suguna \\ Email:vsugunamckmm@gmail.com
}

\begin{abstract}
A comprehensive study of maternal morbidity and mortality with perinatal outcome in patients undergoing elective or emergency caesarean section was carried out on 300 patients undergoing caesarean section, both elective and emergency and their new-borns in the Department of Obstetrics and Gynaecology in Mamata Medical College \& Hospital, Khammam. The study was conducted in 150 consecutive patients from elective group \& 150 consecutive patients from emergency group, who underwent caesarean section and a detailed history from the term gestation patients, were taken. The observations made were tabulated, analyzed and compared with earlier studies. The emergency C-section rates (62.7\%) were more common in the age group of 18-24years than the elective C-section (49.3\%).The pregnancy outcomes in booked mothers(84.7\%) are far more successful than in unbooked mothers(15.3\%). The most common risk factor is Previous LSCS. 42(28\%) patients Elective C-section and 21(14\%) patients in Emergency C-section had previous LSCS. BMI of 63 patients in Elective $C-S$ was ranging between $24.9-29.9 \mathrm{~kg} / \mathrm{m} 2$ when compared to only 35 patients with similar $B M I$ in Emergency $C$-S. Overweight patients underwent more Elective $C-S$ when compared to Emergency $C$-S. There is a reduction of $\mathrm{Hb} \%$ in both elective and emergency groups after caesarean section. In Elective Csections, the indications in 47(31.3\%), 17(11.3\%) and 2(1.3\%) cases were Previous LSCS, Previous 2 LSCS \& Previous 3 LSCS respectively, accounting for total of 66/150(44\%) cases. The 2nd common indication for Elective C-section was CPD, 45/150(30\%). In Emergency C-sections, the most common indication was Foetal distress, 56/300(37.3\%) and 2nd common indication was Previous LSCS, 36/150(24\%) cases. Postpartum Haemorrhage -12(8\%) was the most frequent intra-operative complication in Emergency $C$-S when compared to Elective C-S. Babies weighing 2.5kg or more in the Elective C-S were 119(77.8\%), whereas in Emergency C$S$ were $97(63.4 \%)$ with $P$ value of $<0.001 * *$. This indicates better ANC in the Elective Group. Low birth weight babies (<2.5kg) were $22.2 \%$ and $36.6 \%$ in Elective and Emergency Group respectively $(P=<0.001 * *)$.The Apgar score of $<7$ at 1 minute, in Elective $C$-S were in 25(16.3\%) new-borns and Emergency $C$-S were in $28(18.3 \%)$ new-borns. Neonatal complications are more common in Emergency $C$-section accounting for about $48(31.4 \%)$ new-borns. Sepsis is the most common neonatal complication in Emergency $C$-section accounting for 21/150(13.7\%) new-borns. Hyperbilirubinemia is the most common complication in Elective C-section, accounting for 13/150(8.5\%) new-borns. NICU stay of the new-born was in the range of 3-7days in 33(21.6\%) new-borns in Emergency $C$-S and in 17(11.1\%) new-borns in Elective C-S.
\end{abstract}

Keywords-Emergency, Elective, caesarean section, New-born, morbidity, mortality. 


\section{Introduction}

Caesarean section is the delivery of an infant alive or dead through an abdominal uterine incision after the period of viability ${ }^{[1]-[2]}$.Caesarean section can be considered one the earliest forms of modern birth technology. In the 20th century there have been many new developments in the field of medicine rendering increased safety to all surgical operations, which is mainly due to the availability of antibiotics, safe anesthesia and blood transfusion facilities. The same applies to caesarean section also, which has become an accepted standard procedure among the modern obstetric procedures reducing maternal morbidity and mortality ${ }^{[3]}$.

According to WHO, the C-Section should be restricted to $10-15 \%$ to have a healthy maternal and infant environment. A study by WHO, which reviewed 110,000 births from nine countries in Asia during 2007-2008, 27\% births were by C-section ${ }^{[4]}$. Since 1985 , WHO recommended a $10-15 \%$ of CSection rate in developing countries ${ }^{[5]}$. In India, the incidence of caesarean section is $10-15 \%$. However, the rate of caesarean delivery has increased in the most recent years and in institutional deliveries, the caesarean section rate is as high as $30 \%{ }^{[6]}$.

The aim of this study is to do a clinical study in the patients undergoing elective and emergency caesarean section with respect to the maternal morbidity and mortality, foetal morbidity and mortality.

\section{Materials and Methods}

The present prospective study was carried out on 300 patients undergoing caesarean section, both elective and emergency and their newborns in the Department of Obstetrics and Gynecology in Mamatha Medical College \& Hospital, Khammam, over a period of 2years, from September 2014 to July 2016 after obtaining permission from hospital ethics committee. Group A includes 150 patients from elective surgeries and Group B includes 150 patients from emergency surgeries who underwent caesarean section. Most of the patients were registered in the OPD of our hospital. The patients, who had visited the Antenatal Clinic for 3times or more and fulfill the criteria, were termed as Booked cases. All other patients were termed as Unbooked cases. We have included all patients undergoing of caesarean section and their newborns. Patients with normal vaginal delivery and vaginal birth after caesarean section were excluded.

Detailed histories from the term gestation patients were taken. The procedure of the study was explained and required consent for the study was taken. Examination of the patient was done and all relevant data was obtained. Details of indications for caesarean section, nature of operation, condition of the mother and the perinatal outcome were assessed for post-operative period of 7 days.

\section{Statistical Methods}

Descriptive and inferential statistical analysis has been carried out in the present study. Results on continuous measurements are presented on Mean SD (Min-Max) and results on categorical measurements are presented in Number (\%). Significance is assessed at $5 \%$ level of significance. Student $\mathrm{t}$ test (two tailed, independent) has been used to find the significance of study parameters on continuous scale. Chi-square/ Fisher Exact test has been used to find the significance of study parameters on categorical scale between two or more groups ${ }^{[7]-[9]}$.

\section{RESULTS}

Age: In Group A, $49.3 \%$ of patients are in the age group of 18-24years and in Group B $62.7 \%$ suggesting most of the patients undergoing Csection are in age group of 18-24 year

Table 1: Age distribution of patients who underwent Caesarean section

\begin{tabular}{|l|c|c|}
\hline Age & Elective CS(A) & Emergency CS(B) \\
\hline $18-24$ & $74(49.3 \%)$ & $94(62.7 \%)$ \\
\hline $25-29$ & $56(37.3 \%)$ & $44(29.3 \%)$ \\
\hline $30-34$ & $18(12 \%)$ & $10(6.7 \%)$ \\
\hline $35 \&$ above & $2(1.3 \%)$ & $2(1.3 \%)$ \\
\hline Mean \pm SD & $24.95 \pm 4.02$ & $23.70 \pm 4.05$ \\
\hline
\end{tabular}

Booked patients: Out of 300 patients who underwent C-section, 254(84.7\%) were booked and $46(15.3 \%)$ were unbooked. Out of 46 unbooked 


\section{JMSCR Vol||04||Issue||12||Page 15059-15069||December}

cases, 35(76\%) unbooked patients underwent Emergency C-section suggesting most of the Unbooked patients underwent Emergency C-section

Table 2: Booked / Unbooked cases

\begin{tabular}{|l|c|c|c|}
\hline Type & Elective C-S(A) & Emergency C-S(B) & Total \\
\hline Booked & $139(92.7 \%)$ & $115(76.7 \%)$ & $254(84.7 \%)$ \\
\hline Unbooked & $11(7.3 \%)$ & $35(23.3 \%)$ & $46(15.3 \%)$ \\
\hline Total & $150(100 \%)$ & $150(100 \%)$ & $300(100 \%)$ \\
\hline
\end{tabular}

Distribution of Period of Gestation is statistically similar in two groups with age of 37-39weeks

BMI: In Group A,63 patients had BMI ranging between $24.9-29.9 \mathrm{~kg} / \mathrm{m} 2$ when compared to only 35 patients in Group B. Overweight patients underwent more Elective C-S when compared to Emergency C-S. 46 patients in Group B had BMI ranging between $30-40 \mathrm{~kg} / \mathrm{m} 2$ when compared to only 20 patients with similar BMI in Group A. Obese patients underwent more Emergency C-S when compared to Elective C-S.

Table 3: BMI $(\mathrm{kg} / \mathrm{m} 2)$ of patients studied

\begin{tabular}{|l|c|c|}
\hline BMI $(\mathrm{kg} / \mathrm{m} 2)$ & Elective CS & Emergency CS \\
\hline$<18.5$ & $0(0 \%)$ & $0(0 \%)$ \\
\hline $18.5-24.9$ & $65(43.3 \%)$ & $59(39.3 \%)$ \\
\hline $24.9-29.9$ & $63(42.0 \%)$ & $35(23.3 \%)$ \\
\hline $30-40$ & $20(13.3 \%)$ & $46(30.7 \%)$ \\
\hline$>40$ & $2(1.3 \%)$ & $10(6.7 \%)$ \\
\hline Total & $150(100.0 \%)$ & $150(100.0 \%)$ \\
\hline Mean \pm SD & $26.73 \pm 4.18$ & $25.89 \pm 6.26$ \\
\hline
\end{tabular}

Haemoglobin: In Elective C-section, the Preoperative $\mathrm{Hb} \%$ was $10.81 \pm 1.29($ Mean \pm SD) and Postoperative $\mathrm{Hb} \%$ was $9.65 \pm 1.38$ (Mean $\pm \mathrm{SD}$ ). In Emergency $\mathrm{C}$-section the Preoperative $\mathrm{Hb} \%$ was $10.59 \pm 1.41$ (Mean \pm SD) and Postoperative $\mathrm{Hb} \%$ was $9.38 \pm 1.32 \quad$ (Mean \pm SD). A statistically significant $\mathrm{P}$ value of $<0.001^{* *}$, is obtained suggesting most of the patients following $\mathrm{C}$-section (elective/emergency) are associated with reduction in $\mathrm{Hb} \%$.
Graph 1: Comparison of Pre-operative $\mathrm{Hb} \%$ \& Post-operative $\mathrm{Hb} \%$ in two groups

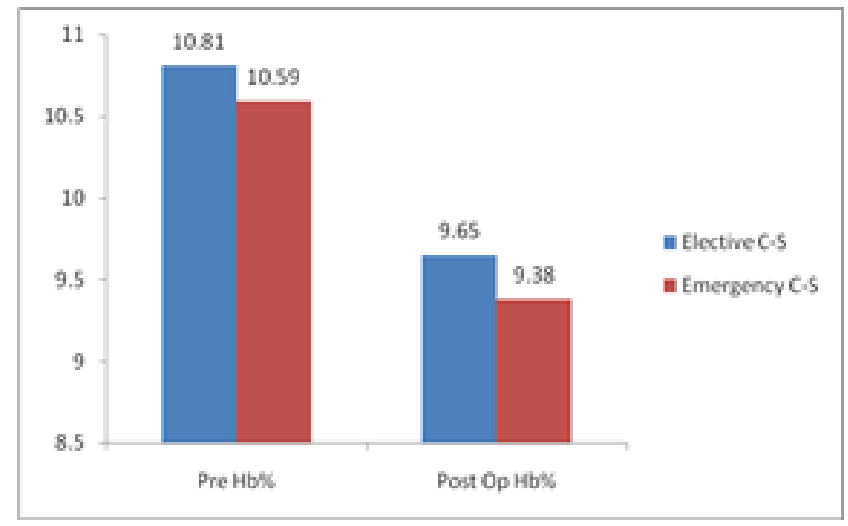

Risk factors: The most common risk factor is Previous LSCS. It can be observed that the patients with risk factor of Previous LSCS are more common with Elective C-S group compared to Emergency C-S group

Table 4 : Risk Factors in Caesarean Section

\begin{tabular}{|c|c|c|}
\hline Risk factors & $\begin{array}{l}\text { Elective C-S } \\
(\mathrm{n}=150)\end{array}$ & $\begin{array}{l}\text { Emergency C- } \\
S(n=150)\end{array}$ \\
\hline N0 & $82(54.7 \%)$ & $93(62 \%)$ \\
\hline Yes & $68(45.3 \%)$ & $57(38 \%)$ \\
\hline 1) Previous LSCS & $42(28 \%)$ & $21(14 \%)$ \\
\hline $\begin{array}{l}\text { 2) Known } \\
\text { hypothyroidism }\end{array}$ & $8 \quad(5.3 \%)$ & $7 \quad(4.7 \%)$ \\
\hline 3) Twin gestation & $3(2 \%)$ & $3(2 \%)$ \\
\hline 4 )Severe CPD & $1 \quad(0.7 \%)$ & $5(3.3 \%)$ \\
\hline 5) Gestation HTN & $4(0 \%)$ & $2(1.3 \%)$ \\
\hline 6)Rh-ve & $0 \quad(0 \%)$ & $3(2 \%)$ \\
\hline 7) IUGR & $2(1.3 \%)$ & $0 \quad(0 \%)$ \\
\hline 8) Pre-eclampsia & $0 \quad(0 \%)$ & $2(1.3 \%)$ \\
\hline 9)Precious pregnancy & $0 \quad(0 \%)$ & $2(1.3 \%)$ \\
\hline 10)secondary infertility & $2(0 \%)$ & $0 \quad(0 \%)$ \\
\hline 11)Placenta previa & $1 \quad(0.7 \%)$ & $1 \quad(0.7 \%)$ \\
\hline 12) Anemia & $1 \quad(0.7 \%)$ & $1 \quad(0.7 \%)$ \\
\hline $\begin{array}{l}\text { 13)Antepartum } \\
\text { eclampsia }\end{array}$ & $0 \quad(0 \%)$ & $1 \quad(0.7 \%)$ \\
\hline 14)Bronchial asthama & $0 \quad(0 \%)$ & $1 \quad(0.7 \%)$ \\
\hline 15)Elderly primi & $1 \quad(0.7 \%)$ & $0 \quad(0 \%)$ \\
\hline 16) breech presentation & $0 \quad(0 \%)$ & $2(1.3 \%)$ \\
\hline 17)left side hemi paresis & $0 \quad(0 \%)$ & $1 \quad(0.7 \%)$ \\
\hline 18)Maternal fever & $0 \quad(0 \%)$ & $1 \quad(0.7 \%)$ \\
\hline $\begin{array}{l}19 \text { )overt DM \&chronic } \\
\text { HTN }\end{array}$ & $1(0.7 \%)$ & $0 \quad(0 \%)$ \\
\hline 20)poliomyelitis & $1 \quad(0.7 \%)$ & $0(0 \%)$ \\
\hline 21)PROM & $0 \quad(0 \%))$ & $1(0.7 \%)$ \\
\hline 22)Transverse lie & $0 \quad(0 \%)$ & $1(0.7 \%)$ \\
\hline 23)Typhoid fever & $0 \quad(0 \%)$ & $1(0.7 \%)$ \\
\hline
\end{tabular}




\section{The most common indication for $\mathbf{C}$-section}

Out of 150 Elective $\mathrm{C}$-sections, the indications in $47(31.3 \%), 17(11.3 \%)$ and $2(1.3 \%)$ cases were Previous LSCS, Previous 2LSCS \& Previous 3 LSCS respectively, accounting for total of $66 / 150(44 \%)$ cases.

The 2nd common indication for Elective C-section was CPD, 45/150(30\%). Out of 150 Emergency Csections, the most common indication was Fetal distress, accounting for total of 56/300(37.3\%) cases. The 2nd common indication for Emergency Csection was Previous LSCS, 36/150 (24\%) cases.

Table 5 Common indication of C-section

\begin{tabular}{|l|c|c|}
\hline Indication & ElectiveCS & Emergency CS \\
\hline 1)Previous LSCS & $47(31.3 \%)$ & $36(24.0 \%)$ \\
\hline 2)Previous 2 LSCS & $17(11.3 \%)$ & $0(0 \%)$ \\
\hline 3)Previous 3 LSCS & $2(1.3 \%)$ & $0(0 \%)$ \\
\hline 4)CPD & $45(30 \%)$ & $5(3.3 \%)$ \\
\hline 5)Fetal distress & $0(0 \%)$ & $56(37.3 \%)$ \\
\hline 6)Failed Induction & $0(0 \%)$ & $15(10 \%)$ \\
\hline 7)PPROM with Fetal Distress & $0(0 \%)$ & $13(8.7 \%)$ \\
\hline 8)Breech & $9(6 \%)$ & $4(2.6 \%)$ \\
\hline 9)Primigravida with breech & $8(5.3 \%)$ & $0(0 \%)$ \\
\hline 11) Abruptio Placenta & $0(0 \%)$ & $5(3.3 \%)$ \\
\hline 12) Contracted Pelvis & $4(2.7 \%)$ & $0(0 \%)$ \\
\hline 13) IUGR & $4(2.7 \%)$ & $0(0 \%)$ \\
\hline 14) Non-Reassuring NST & $1(0.7 \%)$ & $2(1.3 \%)$ \\
\hline $\begin{array}{l}\text { 15) Persistent Direct OP } \\
\text { position }\end{array}$ & $0(0 \%)$ & $2(1.3 \%)$ \\
\hline 16) Severe Oligohydroamnios & $1(0.7 \%)$ & $3(2 \%)$ \\
\hline 17) Transverse lie & $1(0.7 \%)$ & $1(0.7 \%)$ \\
\hline 18) Cord Presentation & $0(0 \%)$ & $2(1.3 \%)$ \\
\hline 19) Antepartum Eclampsia & $0(0 \%)$ & $1(0.7 \%)$ \\
\hline 20) Elderly Primi with CPD & $1(0.7 \%)$ & $0(0 \%)$ \\
\hline 21) Placenta previa Grade IV & $2(1.3 \%)$ & $0(0 \%)$ \\
\hline 22) Scar tenderness & $0(0 \%)$ & $2(1.3 \%)$ \\
\hline Total & $150(100 \%)$ & $150(100 \%)$ \\
\hline
\end{tabular}

Intra operative Complications:

Table 6: Intra operative Complications in C-section.

\begin{tabular}{|l|c|c|}
\hline Intra operative Complications & Elective & Emergency \\
\hline No & $135(90 \%)$ & $98(65.3 \%)$ \\
\hline Yes (below mentioned) & $15(10 \%)$ & $52(34.7 \%)$ \\
\hline Uterine angle extended with Bleeding & $4(2.7 \%)$ & $10(6.7 \%)$ \\
\hline PPH & $1(0.7 \%)$ & $12(8 \%)$ \\
\hline Dense adhesion & $4(2.7 \%)$ & $8(5.3 \%)$ \\
\hline High insertion of bladder & $3(2 \%)$ & $8(5.3 \%)$ \\
\hline Retro placental Clot $\geq 150 \mathrm{ml}$ & $0(0 \%)$ & $1(0.7 \%)$ \\
\hline $\begin{array}{l}\text { Injury to Ascending branch of Uterine } \\
\text { Artery }\end{array}$ & $0(0 \%)$ & $4(2.7 \%)$ \\
\hline Scar Dehiscence & $0(0 \%)$ & $3(2 \%)$ \\
\hline $\begin{array}{l}\text { Adherent bladder to LUS } \\
\text { sdhesions between rectus } \\
\text { sheath and muscle }\end{array}$ & $0(0 \%)$ & $2(1.3 \%)$ \\
\hline Broad ligament Haematoma & $3(2 \%)$ & $1(0.7 \%)$ \\
\hline $\begin{array}{l}\text { Incision extended vertically in the LUS } \\
\text { up to cervix }\end{array}$ & $0(0 \%)$ & $1(0.7 \%)$ \\
\hline
\end{tabular}

Intra-operative complications were more frequent in Emergency C-S when compared to Elective C-S, because the labour has already began, mother is already exhausted, there may some other maternal health concern which emerges during labour and there is not enough time for both the anesthetist and obstetrician. $\mathrm{PPH}$ is the most frequent intraoperative complication in Emergency $\mathrm{C}-\mathrm{S}$ when compared to Elective C-S. Uterine angle extended with bleeding is the 2nd common complication in Emergency C-S.

\section{Post-Operative Complications}

Post-operative complications in were more in emergency caesarean section when compared to elective caesarean section. PPH is the most common followed bywound infection is the 2nd most common complication in Emergency group. 


\section{JMSCR Vol||04||Issue||12||Page 15059-15069||December}

Table 8.post -operative complications in C-section.

\begin{tabular}{|l|l|c|c|}
\hline S.no & $\begin{array}{l}\text { Post-operative } \\
\text { complications }\end{array}$ & Elective CS & Emergency CS \\
\hline A & No & $134(89.3 \%)$ & $70(46.7 \%)$ \\
\hline B & Yes & $16(10.7 \%)$ & $80(53.3 \%)$ \\
\hline 1$)$ & PPH & $5(3.3 \%)$ & $20(13.3 \%)$ \\
\hline 2$)$ & Wound Infection & $2(1.3 \%)$ & $14(9.3 \%)$ \\
\hline 3$)$ & UTI & $2(1.3 \%)$ & $10(6.7 \%)$ \\
\hline 4$)$ & Breast Engorgement & $3(2 \%)$ & $6(4 \%)$ \\
\hline 5$)$ & Puerperal pyrexia & $4(2.7 \%)$ & $10(6.7 \%)$ \\
\hline 6$)$ & $\begin{array}{l}\text { Respiratory } \\
\text { infection }\end{array}$ & $0(0 \%)$ & $6(4 \%)$ \\
\hline 7$)$ & Anemia & $0(0 \%)$ & $8(5.3 \%)$ \\
\hline 8$)$ & Mastitis & $0(0 \%)$ & $2(1.3 \%)$ \\
\hline 9$)$ & Wound gaping & $0(0 \%)$ & $4(2.7 \%)$ \\
\hline
\end{tabular}

Birth weight of newborn babies: Babies weighing $2.5 \mathrm{~kg}$ or more in the Group A (Elective C-S) were 119(77.8\%), whereas in Group B (Emergency C-S) were $97(63.4 \%)$ with $\mathrm{P}$ value of $<0.001 * *$. This indicates better ANC in the Elective Group.Low birth weight babies $(<2.5 \mathrm{~kg})$ were $22.2 \%$ and $36.6 \%$ in Group A and Group B respectively ( $\left.\mathrm{P} \leq 0.001^{* *}\right)$.

Table 8: The birth weight of the newborns.

\begin{tabular}{|l|c|c|}
\hline Birth weight $(\mathrm{kg})$ & Elective CS & Emergency CS \\
\hline$<1.5$ & $0(0 \%)$ & $0(0 \%)$ \\
\hline $1.5-2.5$ & $34(22.2 \%)$ & $56(36.6 \%)$ \\
\hline $2.5-3.5$ & $113(73.9 \%)$ & $93(60.8 \%)$ \\
\hline$>3.5$ & $6(3.9 \%)$ & $4(2.6 \%)$ \\
\hline Total & $153(100 \%)$ & $153(100 \%)$ \\
\hline Mean \pm SD & $2.85 \pm 0.41$ & $2.70 \pm 0.39$ \\
\hline
\end{tabular}

Apgar score of newborns: The Apgar score of $<7$ at 1 minute, in Elective C-S were in $25(16.3 \%)$ newborns and Emergency C-S were in 28(18.3\%) newborns. From the present study, it can be noted that the difference in Apgar score in elective and emergency caesarean section, despite the fetal distress being the most common indication for emergency caesarean section indicating the efficiency of the obstetricians.
Graph 2: Apgar score of newborns delivered by Caesarean Section

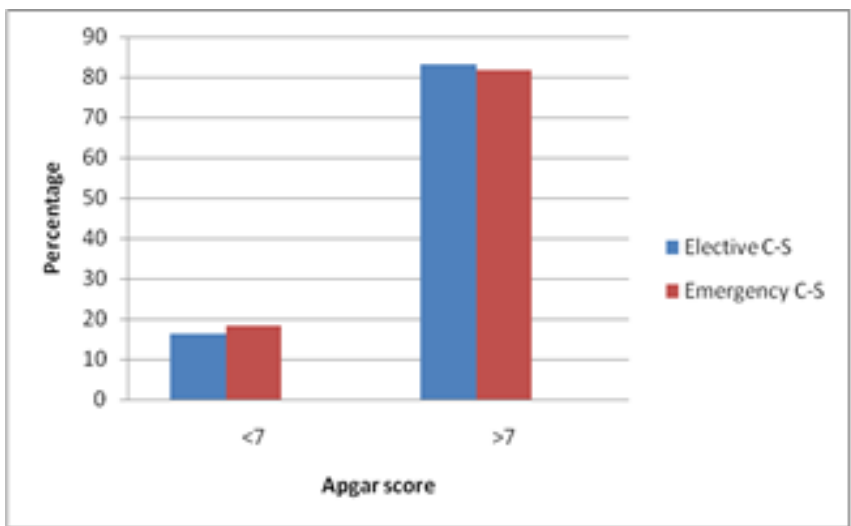

Table 10: Neonatal complications of newborns delivered by Caesarean Section

\begin{tabular}{|l|l|c|c|}
\hline \multicolumn{2}{|l|}{ Neonatal complications } & Elective CS & Emergency CS \\
\hline No & $121(79.1 \%)$ & $107(69.9 \%)$ \\
\hline Yes & Sepsis & $32(20.9 \%)$ & $46(30.1 \%)$ \\
\hline 2) & Hyperbilirubinemia & $13(8.5 \%)$ & $13(8.5 \%)$ \\
\hline 3) & RDS & $6(3.9 \%)$ & $8(5.2 \%)$ \\
\hline 4$)$ & MAS & $4(2.6 \%)$ & $2(1.3 \%)$ \\
\hline 5$)$ & Fever & $0(0 \%)$ & $1(0.7 \%)$ \\
\hline 6$)$ & Neonatal Seizure & $1(0.7 \%)$ & $0(0 \%)$ \\
\hline 7$)$ & Neonatal death & $0(0 \%)$ & $1(0.7 \%)$ \\
\hline
\end{tabular}

Neonatal complications is statistically significant with Emergency $\mathrm{C}-\mathrm{S}$ with $\mathrm{P}=0.026^{*}$ compared to Elective group. Sepsis is the most common complication in Emergency $\mathrm{C}$-section accounting for $21 / 150(13.7 \%)$ newborns. Hyperbilirubinemia is the most common complication in Elective Csection, accounting for 13/150(8.5\%) newborns.

NICU stay of newborns NICU stay were significantly more associated with Emergency C-S with $\mathrm{P}=0.002 * *$

Graph 3: NICU stay of newborns

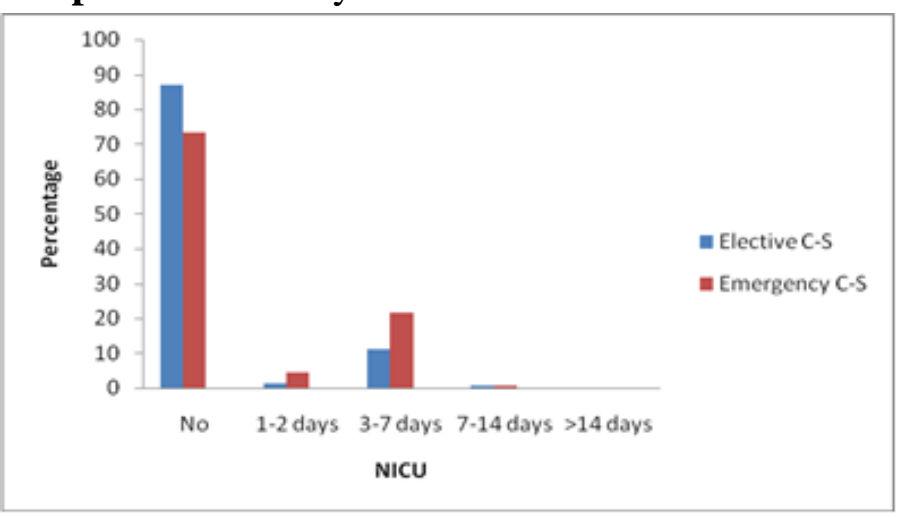




\section{DISCUSSION}

The present study is a comparative study of maternal and neonatal morbidity, mortality in patients who undergo caesarean section (either elective or emergency). The estimate of Caesarean section rates in India is $7.1 \%$ in the year 1998 and $16.7 \%$ in the year 2006. Caesarean section rates were $18-23 \%$ in the United States and in United Kingdom ${ }^{[10]}$.

Age at the time of caesarean section: A study conducted by Ecker JL \& co-workers ${ }^{[11]}$ at women hospital, observed caesarean delivery rates increased with advancing maternal age. In the present study, the emergency $\mathrm{C}$-section rates (62.7\%) were more common in the age group of 18-24years than the elective C-section $(49.3 \%)$ but in the age group of 25-29 years the elective $\mathrm{C}$-section rates $(37.3 \%)$ were common than the emergency Csection rates $(29.3 \%)$. In the age group of 3034 years the elective $\mathrm{C}$-section rates 18 (12\%)were common than the emergency $\mathrm{C}$-section rates $10(6.7 \%)$ but in the age group of 35 and above both elective $\mathrm{C}$-section and emergency $\mathrm{C}$-section rates were same $(1.3 \%)$.

A study conducted by Thakur V\& co-workers ${ }^{[12]}$ observed emergency $\mathrm{C}$-section rates $(58.15 \%)$ were common 18-24 years than elective $\mathrm{C}$-section $52.01 \%$, in age group 25-29yrs elective C-section rate $(46.12 \%)$ are more than elective $\mathrm{C}$-section rate $(35.81 \%) \mathrm{n}$ and in age group 30-35 yrs emergency c_section $(6.03 \%)$ are more than elective (1.86\%).

Booked/Unbooked case: Pregnancy is the most important period in the life of woman; extraordinary care is therefore given by the healthcare system of most countries ${ }^{[13]}$. Antenatal care is the care of the woman during pregnancy whose primary aim is to achieve healthy mother and the healthy baby ${ }^{[14]}$. Antenatal care has been intensified over the last two decades due to the advent of primary health care and global efforts towards safe motherhood. Among the Millennium Development Goals set in the year 2000 three quarters reduction in the maternal and infant mortality rates by the year 2015 were targeted ${ }^{[15]}$. Maternal and neonatal complications during the perinatal period are highly associated with non- utilization of antenatal and delivery care services and poor socioeconomic conditions of the patient. These complications were more common with unbooked than booked patients.

Body Mass Index: In the present study, 63 patients in Elective C-S had BMI ranging between 24.9$29.9 \mathrm{~kg} / \mathrm{m} 2$ when compared to only 35 patients with similar BMI in Emergency C-S. Overweight patients underwent more Elective $\mathrm{C}-\mathrm{S}$ when compared to Emergency C-S.Six patients in Emergency C-S had BMI ranging between 30-40 $\mathrm{kg} / \mathrm{m} 2$ when compared to only 20 patients with similar BMI in Elective C-S. Obese patients underwent more Emergency $\mathrm{C}-\mathrm{S}$ when compared to Elective C-S.

Obesity is a well-established risk factor for requiring a Caesarean section. Many associated factors such as maternal age, gestational diabetes, preeclampsia and macrosomia play important roles in this association as true confounding variables ${ }^{[16]}$. Overweight and obese pregnant women are also at increased risk for instrumental deliveries like forceps, vacuum extraction. These procedures are not completely free of risk even among women of a normal body constitution ${ }^{[17]}$.

Haemoglobin Level: The ability of pregnant women to withstand blood loss at the time of delivery depends on the haemoglobin level, the blood volume, the volume of blood loss, any associated co-existing disease and complications. Accurate estimation of blood loss at the time of $\mathrm{C}$ section delivery is important in transfusion practice.60. It is difficult to estimate the blood loss accurately in this surgery because of dispersion of blood loss and secondly due to blood being mixed with amniotic fluid. Studies done in the 60's using various techniques have mentioned the average blood loss between 930 and $1106 \mathrm{ml}^{[18]}$.

Duthie and co-workers used alkaline haematin method to measure blood loss in forty women with singleton pregnancies undergoing lower segment $\mathrm{C}$ section and general anesthesia. The mean measured blood loss was found to be $487 \mathrm{ml}$ (range 164ml $1438 \mathrm{ml}$ ) and was estimated by the observer by reasonable accuracy ${ }^{[19]}$. In the present study an 
attempt was made to compare the amount of $\mathrm{Hb} \%$ drop in elective and emergency C-S. A statistically significant reduction in $\mathrm{Hb} \%$ is obtained with both elective and emergency caesarean section suggesting most of the patients need improvement in their blood levels section.

Risk Factors: Most of the textbooks describe that Repeat caesarean section was the commonest risk factor for subsequent caesarean section ${ }^{[20]}$. In the present study, the most common risk factor is previous LSCS. 42 (28\%) patients had previous LSCS in Elective C-section and 21(14\%) patients had previous LSCS in Emergency $\mathrm{C}$-section. The second most common risk factor in Elective C-S (5.3\%) and Emergency C-S (4.7\%) was known case of Hypothyroidism. The rate of Elective caesarean section was more compared to Emergency caesarean section in patients with history of previous LSCS.

The Indications for Caesarean sections: A study was done to see for the most frequent indication for the elective and emergency caesarean sections. It was noted that most frequent indication for the elective caesarean section were previous caesarean section, breech presentation, cephalopelvic disproportion and/or pregnancy after IVF/ET (In Vitro Fertilisation/Embryo Transfer). While the most frequent indication for the emergency caesarean section was preeclampsia, vaginal bleeding/ abruption placentae, breech presentation and secondary inertia of the uterus ${ }^{[21]}$. Another study was done by khan and co-worker, in which $82.07 \%$ of cases, caesarean section was performed as an emergency procedure and in $17.92 \%$ of cases the operation was performed as an elective procedure. Elective repeat caesarean sections were usually performed for cephalopelvic disproportion [18].

In the present study the most common indication for C-section in $83 / 300$ cases were Previous LSCS accounting for $27.7 \%$ cases of C-section. Out of 150 Elective C-sections, the indications in $47(31.3 \%)$, $17(11.3 \%)$ and $2(1.3 \%)$ cases were Previous LSCS, Previous 2 LSCS \& Previous 3 LSCS respectively, accounting for total of $66 / 150(44 \%)$ cases. The 2 nd common indication for Elective C-section was CPD, 45/150 (30\%). Out of 150 Emergency C-sections, the most common indication were foetal distress, $56 / 300(37.3 \%)$ and 2nd common indication were Previous LSCS, 36/150(24\%) cases. Hence in the present study, it can be stated that the most common indication for elective caesarean section was Previous LSCS, whereas in Emergency caesarean section it was foetal distress.

Intra-operative and post-operative complications: High emergency caesarean delivery rates were associated with increased fresh stillbirths, neonatal deaths, and severe neonatal morbidity, which remained significant even after adjusting for other factors. High elective caesarean delivery rates were associated with fewer fresh stillbirths and neonatal deaths. Since the majority of emergency caesarean deliveries were performed for dystocia and foetal distress, it is likely that a significant proportion of the perinatal deaths and severe newborn morbidity was related to birth asphyxia secondary to prolonged labor and that the interventions may have been performed too late. Close monitoring of labor, early detection of complications and timely decision for caesarean delivery are crucial ${ }^{[22]}$.

The commonest complication was haemorrhage > $1000 \mathrm{ml}$ in majority of emergency caesarean section cases, which occurred due to uterine a tony and abnormal adherence of placenta ${ }^{[23]}$.A retrospective study the overall maternal intra-operative complication rate was $14.8 \%$ includes lacerations of the uterine corpus $(10.1 \%)$ and blood loss $\geq 1000 \mathrm{ml}$ (7.3\%). The overall maternal postoperative morbidity rate was $35.7 \%$. Fever $(24.6 \%)$, blood loss between 1000 and $1500 \mathrm{ml}$ (4\%), haematoma $(3.5 \%)$ and urinary tract infections $(3.0 \%)$ were the most frequent complications. The elective group showed significantly lower complication rates compared to the emergency group ${ }^{[24]}$. In the present study, Postpartum Haemorrhage was the most frequent intra-operative complication in both groups followed by Extension of Uterine angle with bleeding, Wound infection seen in Emergency Csections, Puerperal pyrexia- 4 (2.7\%) in Elective Csections. 
The birth weight of the newborns delivered by caesarean section: Low Birth Weight is closely associated with foetal and perinatal mortality and morbidity, inhibited growth and cognitive development, and chronic diseases later in life.

At the population level, the proportion of babies with a LBW is an indicator of a multifaceted publichealth problem that includes long-term maternal malnutrition, ill health and poor health care in pregnancy. On an individual basis, LBW is an important predictor of newborn health and survival and is associated with higher risk of infant and childhood mortality ${ }^{[25]}$. Low birth weight constitutes as $60-80 \%$ of the infant mortality rate in developing countries. Infant mortality due to low birth weight is usually a direct cause resulting from other medical complications such as preterm birth, poor maternal nutritional status, lack of prenatal care, maternal sickness during pregnancy and an unhygienic home environment. According to an analysis by University of Oregon, reduced brain volume in kids is also related to low birth-weight.

The American College of Obstetricians and Gynaecologists and medical policy makersreviewed research studies and found an increased incidence of sepsis, RDS, hypoglycaemia, need for respiratory support, need for NICU admission, and need for hospitalization $>5$ days. In the case of caesarean sections, rates of respiratory death were 14times higher in 37weeks gestation compared with 40 weeks gestation, and 8.2 times higher for caesarean at 38 weeks. In this review, no studies found decreased neonatal morbidity due to nonmedically indicated (elective) delivery prior to 39 weeks ${ }^{[26]}$.

In the present study, Low birth weight was more common in emergency caesarean section - 56 $(36.6 \%)$ than elective caesarean section - 34(22.2\%). $113(73.9 \%)$ newborns had the birth weight ranging between $2.5-3.5 \mathrm{kgs}$ in elective caesarean section, while only $93(60.8 \%)$ had the birth weight ranging between $2.5-3.5 \mathrm{kgs}$ in emergency caesarean section. Apgar score of the newborns: The test is generally done at one and five minutes after birth and may be repeated later if the score is and remains low. Scores
7 and above are generally normal, 4 to 6 fairly low and 3 and below are generally regarded as critically low. A low score on the one-minute test may show that the neonate requires medical attention but is not necessarily an indication that there will be longterm problems, particularly if there is an improvement within 5 minutes. If the Apgar score remains below 3 at later times such as 10,15 , or 30 minutes, there is a risk that the child will suffer longer-term neurological damage. There is also a small but significant increase of the risk of cerebral palsy. However, the purpose of the Apgar test is to determine quickly whether a newborn needs immediate medical care; it was not designed to make long-term predictions on a child's health ${ }^{[27]}$. Babies born by caesarean are 50\% more likely to have lower Apgar scores than those born vaginally [28].

In the present study, the Apgar score of $<7$ at 1 minute, in Elective C-S were in $25(16.3 \%)$ newborns and Emergency C-S were in 28(18.3\%) newborns. From the present study, it can be noted that no difference in Apgar score in elective and emergency caesarean section, despite the foetal distress being the most common indication for emergency caesarean section .

Babies delivered through caesarean birth have lower Apgar scores. The low score may be an effect of the anesthesia. It can also be that the baby may have been in distress to begin.

The complications in the newborns delivered by Caesarean section: Neonatal complications have received the greatest attention in the evaluation of neonatal outcomes by caesarean section. Among these, respiratory distress syndrome is one of the common complications. It has been stated that caesarean section is an independent risk factor for predicting respiratory distress syndrome ${ }^{[29]}$. In the present study, neonatal complications are more common in Emergency C-section accounting for about 48 (31.4\%) newborns. Sepsis is the most common neonatal complication in Emergency Csection accounting for $21 / 150(13.7 \%)$ newborns. The second common complication is hyperbilirubinemia, accounting for 13/150(8.5\%) newborns. 
NICU stay of newborns delivered by Caesarean section:

Neonatal intensive care units (NICUs) provide care for newborns in need of specialized medical attention.

A study by Liston and co-workers ${ }^{[30]}$ on term singleton live-birth deliveries with no congenital anomalies found that NICU admission rates were higher for babies delivered by C-section. Fogelson

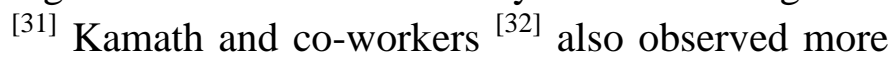
elective repeat $\mathrm{C}$-section babies were admitted to the NICU. Tita and co-workers ${ }^{[33]}$ reported early delivery before 39 weeks for elective C-section in the United States was associated with an increase in admission to NICU.Fallah $\mathrm{S}$ reported that, the period of stay in NICU of the newborns delivered through $\mathrm{C}$-section were more likely to be 28 days of birth than those delivered vaginally ${ }^{[34]}$.

In the present study, NICU stay of the newborn was in the range of 3-7days in 33(21.6\%) newborns in Emergency C-S and in $17(11.1 \%$ ) newborns in Elective C-S. The duration of stay for NICU admitted newborns was more for babies born by Emergency C-sectionsaccounting for 33 (21.6\%) newborns.

\section{Conclusion}

In present day scenario when the access to obstetric care is growing day by day there has been a concern over the rising caesarean rates over the world. Caesarean section is the surgical intervention in case of serious delivery complications. This surgical procedure has been saving lives for a long period of time. The concern for the caesarean rates is due to its rapid increase over the period.

The women in the high risk age group are having less $\mathrm{C}$-section and the women in the low risk age group have higher caesarean births. The relationship with caesarean birth and Antenatal care is not to our expectation, because women having full ANC are having more caesarean. Pregnancy and delivery complications are major determinants of caesarean births. When treatment seeking behaviour of the women of those women who have pregnancy complication are considered the results showed that there is higher chance of caesarean birth for the those who have sought treatment for their complications. It is unfortunate that a number of expecting mothers with pregnancy related risk factors remain unaware of the situation and ultimately they present as an acute emergency i.e. eclampsia fits, antepartum haemorrhage and other complications.

Public health education is the most important factor and the people should realize that government has established health facilities for the common masses and they must avail the available facilities. Primary health providers and traditional birth attendant must be educated regarding the risks of injudicious use of oxytocics without proper assessment and the dangers of the obstructed labour. They should refer the cases a bit earlier to reduce the incidence of maternal as well foetal morbidity and mortality.

Caesarean section rate can be reduced by combined efforts at all levels and by encouraging hospital vaginal deliveries of all the primigravida, grandmultiparous pregnant women and those who had previous caesarean section, provided adequate foetal monitoring and operative facilities are available. Government should improve the existing health facilities, so that antenatal and delivery services should be provided to all the pregnant women in the society.

\section{Acknowledgement}

The heading of the Acknowledgment section and the References section must not be numbered.

\section{References}

1. Cunningham FG, Leveno KJ, Bloom SL, Hauth JC, Rouse DJ, Spong CY. Williams Obstetrics, 23rdedn. Chapter 25. Cesarean Delivery and Peripartum Hysterectomy. McGraw Hill, NewYork; 2010: 544-55

2. Definition of Caesarean section. Medicine Net. Com. Medterms medical dictionary a- z list. Caesarean definition.Availablefrom URL http://search.medicinenet.com/search/search_results/default.aspx?Searchwhat $=1 \&$ query $=\mathrm{c}$ section $\& \mathrm{I} 1=$ Search 
3. Rein Verdult caesarean birth : psychological aspects in adults. Int .J. of prenatal and perinatal psychology and medicine 2009 ;21 (1) : $17-36$

4. Kounteya Sinha. The Times of India. Featured Articles About Lancet - 2013:May 29, Page 5 Available from URL:http://articles.timesofindia.indiatimes.com/keywor $\mathrm{d} /$ lancet/featured/5

5. World Health Organization. Appropriate technology for birth. Lancet 1985; 2(8452):436-37.

6. Mukherjee $\mathrm{S}$ N. Rising caesarean section rate. J ObstetGynecol India 2006; 56(4): 298-300.

7. Bernard Rosner. Fundamentals of Biostatistics, 5thedn, Duxbury, 2000. 80-240.

8. Robert H Riffenbur. Statistics in Medicine, 2ndedn, Academic press. 2005. 85-125.

9. Sunder Rao $P$ S S, Richard J. An Introduction to Biostatistics, A manual for students in health sciences, New Delhi, India. 4thedn, 2006. 86-160.

10. Notozon FC, Plack PJ, Taffel SM. Comparison of national caesarean section rates. N Engl J Med 1987; 316: 386.

11. Ecker JL, Chen KT, Cohen AP, Riley LE, Lieberman ES. Increased risk of cesarean delivery with advancing maternal age: indications and associated factors in nulliparous women. Am J Obstet Gynecol. 2001; 185(4):883-7.

12. Thakur V ChiheriyaH, Thakur A, Mourya S . Study of Maternal and Fetal Outcome in Elective and Emergency Caesarean Section .int J med Ress Rev 2015; 3 (11):1300-1305 .doi

17511/ijmrr.2015.i11.236.

13. Banta D .what is the efficacy / effectiveness of antenatal care and the financial and organizational implication ? copenhangen, WHO regional office for Europe, health evidence network report. 2003.available from: URL : http:// www.euro . who .int/Document /E82996.pdf,accessed on 20/03/12

14. Dolin PJ, Raviglione MC, Kochi A: Global tuberculosis incidence and mortality during 1990-2000. Bull World Health Organ 1994; 72:213-20.

15. World Health Organization. Global tuberculosis control. WHO report 2004. Geneva. Switzerland, 2004

16. Castro LC, Avina RL. Maternal obesity and pregnancy outcomes. CurrOpinObstet Gynecol. 2002; 14: 601-6.

17. Barau G, Robillard PY, Hulsey TC, Dedecker F, Laffite A, Gérardin $\mathrm{P}$ et al. Linear association between maternal prepregnancy body mass index and risk of caesarean section in term deliveries. BJOG. 2006; 113:1173-77.

18. Khan F A, Khan M, Ali A, Chohan U. Estimation of blood loss during Caesarean Section: an audit.J Pak Med Assoc. 2006; 56(12): 572-75.

19. Duthie SJ, Gosh A, NgA, Ho PC. Intraoperative blood loss during elective lower segment caesarean section. $\mathrm{Br}$ J ObstetGynaecol. 1992; 99: 364-7.

20. Haider G, Zehra N, Munir A A, Haider A. Frequency and indications of caesarean section in a tertiary care hospital. Pak J Med Sci. 2009; 25 (5): 791-96.

21. Elvedi-Gasparovic V, Klepac-Pulanic T, Peter B. Maternal and Fetal Outcome in Elective versus Emergency Caesarean Section in a Developing Country. Coll. Antropol. 2006; 30 (1): 113-18.

22. Villar J, Valladares E, Wojdyla D, Zavaleta N, Carroli G, Velazco A, et al. Caesarean delivery rates and pregnancy outcomes: the 2005 WHO global survey on maternal and perinatal health in Latin America. Lancet 2006; 367(9525): 1819-29.

23. Raees M, Yasmeen S, Jabeen S, Utman N, Karim R. Maternal morbidity associated with emergency versus elective caesarean 
section. J Postgrad Med Inst. 2012; 27(1): 55-62.

24. Van Ham MA, Van Dongen PW ,Mulder $\mathrm{J}$.maternal consequences of caesarean section . A retrospective study of intraoperative and postoperative maternal complications of caesarean section during a 10 year period. European journal of obstetrics \&gynecology and reproductive biology 1997 ; 74 (1): 1-6

25. Stevens-Simon C, Orleans M. Low birth weight prevention programs: the enigma of failure. Birth. 1999; 26(3):184-91.

26. Main E, Oshiro B, Chagolla B, Bingham D, Dang-Kilduff L, and Kowalewski L. Elimination of Non-medically Indicated (Elective) Deliveries Before 39 Weeks Gestational Age. California Maternal Quality Care Collaborative Toolkit to Transform Maternity Care, the California Department of Public Health; Maternal, Child and Adolescent Health Division; 1st edition, March of Dimes, July 2010.

27. Casey B M, McIntire D D, Leveno K J. "The continuing value of the Apgar score for the assessment of newborn infants". N Eng J Med. 2001; 344 (7): 467-71.

28. Annibale DJ. Comparative neonatal morbidity of abdominal and vaginal deliveries after uncomplicated pregnancies. Arch PediatrAdolesc Med 1995; 149(8): 862-67.

29. Richardson BS, Czikk MJ, daSilva O, Natale $\mathrm{R}$. The impact of labour at term on measures of neonatal outcome. Am J Obstet Gynecol. 2005:192; 219-26.

30. Liston FA, Allen VM, O'Connell CM, Jangard KA. "Neonatal Outcomes with Caesarean Delivery at Term." Archives of Diseases in Childhood: Fetal and Neonatal Education. 2008; 93: F176-82.

31. Fogelson NS, Menard MK, Hulsey T, Ebeling M. "Neonatal Impact of Elective Repeat Cesarean Delivery at Term: A Comment on Patient Choice Cesarean
Delivery." American Journal of Obstetrics and Gynecology. 2005; 192: 1433-36.

32. Kamath BD, Todd JK, Glazner JE, Lezotte D, Lynch AM. "Neonatal Outcomes after Elective Cesarean Delivery." American Journal of Obstetrics and Gynecology. 2009; 113(6): 1231-38.

33. Tita ATN, Landon MB, Spong CY, Lai Y, Leveno KJ, Varner MW. "Timing of Elective Repeat Cesarean Delivery at Term and Neonatal Outcomes." New England Journal of Medicine. 2009; 360(2): 111-20.

34. Fallah S, Chen X, Lefebvre D, Kurji J, Hader J, Leeb K. Babies Admitted to NICU/ICU: Province of Birth and Mode of Delivery Matter. Healthcare Quarterly. 2011; 14(2): 16-20. 